\title{
Correspondence
}

\section{Seclusion of patients}

DeAr Sirs

Many congratulations on publishing the procedures for the seclusion of patients in the Bethlem Royal and Maudsley Hospitals (Bulletin, November 1982, 6, 199-200).

While the use of seclusion in a hospital setting may have been acceptable twenty years ago, I would suggest that the implementation of modern ideas about the care and management of psychiatric patients leaves no room for the concept of 'solitary confinement' as a way of dealing with disturbed people, either in an emergency or as part of a planned programme of treatment prescribed by a clinical team.

J. A. Winliams

Bryn-y-Neuadd Hospital

Llanfairfechan

Gwynedd

\section{Care in the community}

Dear Sirs

The Government's proposals call for hostels for long-stay patients run by Social Services Departments. For the care of such patients Social Work Departments would have to recruit Mental Nurses. In the Health Service good nurses can achieve status and seniority through the excellence of their clinical work. The nursing profession is beginning to learn that the good clinical nurse requires recognition. They are beginning to attach less importance to long administrative hierarchies. We have just opened this hospital's first hostel for long-stay patients. Nursing morale is superb. It is clear that good work at the hostel will be recognized within the service.

In 1971/4 I had the unusual experience of secondment to a Social Services Department to establish within it a therapeutic community for drug abusers, Alpha House. This was a good three years and I acquired a lasting affection for social work. However, I learned that social work is hierarchical to a degree that doctors can hardly comprehend. Virtually all administrators are former social workers. The almost automatic response to any problem is the appointment of an additional adviser or planner: rarely is there an attempt to improve the quality of actual social work. Promotion to senior post and consequent status is confined to qualified social workers, but subject to this, youth and brief experience of actual social work is no bar. What is more, within social work the residential worker has inferior status. With rare exceptions, such as the Principals of Assessment Centres, the work of the residential social worker is circumscribed and supervised by advisers and seniors qualified in field work.
With their present management practice and duties Social Work Departments may not run long-stay hostels particularly well. The nurses they will have to employ risk becoming second class citizens without real status. Only by retraining as social workers can they hope for improved status or seniority. If Social Work Departments are going to take over our patients, we shall have to try and help them in a way that will require a great deal of tact on our part. For myself I find it a daunting prospect.

IAN G. ChrISTIE

Knowle Hospital

Fareham, Hants

\section{The Approval Exercise}

\section{DeAR SIRS}

Dr Edwards makes some important points (Bulletin, November 1982, 6, 201-2) concerning my article 'The trials of a Convener of an Approval Team' (Bulletin, August 1982, 6, 132-4). Like him, I emphasized that it was becoming increasingly difficult to obtain improved facilities by means of proposing the Unapproved category, because of severely limited finances. But we should remember that the DHSS has made it clear that psychiatry in general should be spared cuts, having been deprived of resources for so long in relation to the more glamorous acute specialties. Should we bow to the inevitability of the economic situation and accept progressively declining clinical standards, or should the College maintain pressure to keep up adequate training with which will be associated adequate clinical care?

However, it seems to me that in the future practicality will dictate that fewer psychiatric units and hospitals will have the resources to train junior psychiatrists and this will involve restructuring of the medical staffing of a hospital. There will need to be more consultants, who might be helped by those in non-training grades such as clinical assistants and hospital practitioners. This might have to happen if a hospital is made Unapproved, although in these circumstances the status of the trainees in post is protected up to the end of their contracts. Some might argue that with more consultants for a hospital patient care would be improved because patients would be more often seen by experienced doctors. I should point out that it is definitely possible, although not easy, for a hospital to be regraded from Unapproved to Provisionally Approved, and then to Approved. I myself know one that has managed this.

In the same issue of the Bulletin, Dr Frost suggested that every Approval Visit should involve a senior registrar. I would agree with this completely and I am aware of the College encouraging Conveners to take a senior registrar along, and the value of that member of the team has been clearly shown in Dr Frost's letter. However, I report two 